\title{
Needle Stick and Sharp Objects Injuries Infection Prevention and Control Guidelines among Health Care Students: Descriptive, Cross Sectional Study
}

\author{
Dalia M. Mohsen ${ }^{1}$, Rawhia Dogham ${ }^{* 2,3}$, Asmaa Saber Ghaly ${ }^{2,4}$ \\ ${ }^{1}$ Prof. of Microbiology and Clinical Laboratories Sciences Department Chair, Inaya Medical College, Riyadh, KSA \\ ${ }^{2}$ Lecturer, Faculty of Nursing, Alexandria University, Egypt \\ ${ }^{3}$ Nursing Department Chair, Inaya Medical College, Riyadh, KSA \\ ${ }^{4}$ Assistant Professor, King Faisal University, Applied Medical Sciences College, Nursing Department, KSA \\ * Corresponding author: Rawhia Dogham; dr.Rawhia_edu@ yahoo.com
}

Received 26 July 2019;

Accepted 02 August 2019;

Published 21 August 2019

\begin{abstract}
Background: Percutaneous exposure to contaminated needle sticks and other sharps is a danger not only to health care workers but also to nursing and paramedical students that increases the morbidity and mortality from infections with blood borne pathogens. Knowledge concerning the general precautions is vital for the prevention of such accidents. This study aimed to describe the knowledge and practice of infection prevention and control guidelines among health care students regarding needle stick and sharp objects injuries. Methods: A descriptive, cross sectional research design was used. Health care students were selected using convenience sampling which included 90 students. Data was collected using a self-reporting structured online questionnaire and administered to a number of health care students including nursing and Clinical laboratory specialists. Results: It was found that about half $(49 \%, 52 \%)$ of the students had fair knowledge and fair practice regarding needle stick injuries and infection control guidelines respectively. The majority of the students (76.7\%) had positive attitudes towards Needle stick injuries and infection control guidelines. Conclusion: This study concluded that knowledge and practice of health care students about the risk associated with needle-stick and sharp objects injuries and use of preventive measures was fair. Special concerns should be given to the role of post exposure prophylaxis, the recapping of needles and the importance and mechanism of reporting NSIs. Standing operating procedures should be conveyed regarding needle-stick and sharp objects injuries in all the health facilities.
\end{abstract}

Keywords: Needle stick injury, infection prevention and control, nursing students, sharp object, blood borne diseases

\section{Introduction}

Increase in the frequency of deadly infections due to more exposure to microorganisms and viruses that cause blood-borne diseases, has led the medical community to initiate efforts to prevent and limit exposure among health care workers (HCWs). ${ }^{[1]}$ Needle stick injuries (NSIs) are one of the common health hazards among HCWs. It not only carries a risk of transmission of blood borne pathogens but also represents quality health care services. The risk of injury depends on two basic factors; the number of infectious patients and the universal precautions taken by the HCWs. Considering every patient to be infectious and following the universal discipline during handling of sharps remains to be the gold standard for the prevention of NSIs. ${ }^{[2,3]}$

NSIs mean a percutaneous wound caused by needle point and other sharp instruments, including lancets, scalpels, and contaminated broken glass. ${ }^{[4]}$ Nursing, medical and paramedical students are still on high risk for exposure to blood-borne diseases such as
Hepatitis-B (HBV), Hepatitis-C (HCV) and human Immunodeficiency virus (HIV) through needle stick and sharp objects injuries during their clinical training. ${ }^{[5]}$ It was evidenced that, 3 million of HCWs out of 35 million of them experienced NSIs each year internationally. Furthermore, NSI prevalence in Arab countries according to some researches done in Egypt, Jordan, and Kingdom of Saudi Arabia (KSA) were 68\%; 75.5\%; and $46.9 \%$, respectively. ${ }^{[6-9]}$

The risk of sharps injuries is higher in surgical staff compared to the other HCWs in particular; medical, nursing and clinical laboratory students and trainees have reported the highest rate of injuries. ${ }^{[10,11]}$ Another research performed among medical students and senior faculties reported a $28 \%$ rate of injuries in medical students and $100 \%$ in faculty. ${ }^{[10]}$ In addition, during clinical training of different nursing specialties, it was reported that NSIs occurred more in gynecology than in any other surgical specialties, with rates of $10 \%$ during abdominal hysterectomy, $21 \%$ during 
vaginal hysterectomy, and 6-10\% of gynecologic procedures overall. $^{[12,13]}$

The students can be exposed to sharps injuries during performing their clinical procedures skills such as during recapping, opening of ampoule or vial, disposal of syringes, suturing, measuring blood sugar and administration of injections. ${ }^{[5]}$ This risk may lead to physical and psychological problems which affecting the students' life as well as the future functioning in their work. ${ }^{[14]}$ Examples of psychiatric disorders; depression, post- traumatic stress disorder and adjustment disorder. ${ }^{[15]}$

Three intervention strategies are used in occupational health for preventing sharp injuries and splash exposures. First, elimination or management of the workplace hazards. Second, prevention of infectious disease and associated disabilities. Third, changes in HCWs and students' knowledge, abilities, and behavior. ${ }^{[16]}$ Educators are also play a vital role regarding the performance of their students as they offer inadequate supervision of students in the clinical area. Moreover, improved awareness on occupational safety among nursing and paramedical students may lead to decrease the risk of needle stick and sharp objects injuries. ${ }^{[17]}$

Due to the increased danger of needle stick and sharp objects injuries among health care students, so the aim of this study was to determine the incidence of NSIs and to assess the knowledge and practice of nursing and clinical laboratory students regarding needle stick and sharp objects injuries infection prevention and control guidelines.

\section{Materials and Method}

\subsection{Study design and setting}

This descriptive, cross sectional study was carried out during the 2nd semester of academic year 2018/2019 in Nursing and Clinical Laboratory Sciences departments at Inaya Medical College Riyadh, KSA.

\subsection{Study population and sampling}

A convenience sample of 90 clinical laboratory and nursing students agreed to participate in this study. Only, the students who started their clinical training were included in this study.

\subsection{Tool:}

The Needle Stick and Sharp Objects Injuries Questionnaire was used to collect data from the students. It was developed by the researchers after reviewing the relevant literatures. ${ }^{[3,18-21]}$ It consists of the following parts:

Part 1: Sociodemographic data which includes age, sex, specialty and educational level.

Part 2: Knowledge related to needle stick and sharp objects injuries. It includes 21 questions which classified into Multiple Choice Questions, yes or no, and open ended questions. The questions were related to the incidence and pattern, universal precautions, availability of preventive measures, and reporting system.

Part 3: Practices related to needle stick and sharp objects injuries. It includes 6 questions which answered using done and not done.

Part 4: student's attitudes toward needle stick and sharp objects injuries. It consist of 15 statements which answered using a four four-point Likert scales ranged from: strongly agree to strongly disagree. The students' knowledge and practice cut of scores were calculated and summarized then converted to percent score which categorized into poor, for those who have a score $<50.0 \%$, fair, for those who have a score of $50.0 \%$ to $<75.0 \%$ and good, for those who have a score $\geq 75.0 \%$. Moreover, the students' attitude were summarized and converted to percent score as: the data are positive for a score $\geq 60 \%$, whereas they are negative when the score was $<60 \%$.

\subsection{Study procedures}

An official permission was obtained for data collection from the institutional research board at the selected college. The tool was developed by the researchers after review of the related literature. The tool was tested for content validity by experts in the area of the study and the needed modifications were done. Pilot study was performed on 10 students to assess the clarity of the tool, and after that the required modifications were made. Students of the pilot study were excluded from the study sample. Reliability of the tool was assessed by using Cronbach's Alpha coefficient statistical test which revealed an accepted value of 0.84 . After that, the questionnaire was published online to be filled by the students. Students' information and responses were treated anonymously and confidentiality was assured.

\subsection{Statistical analysis of the data}

Data were fed to the computer and analyzed using IBM SPSS software package version 20.0. Data were described using mean and standard deviation. Significance of the obtained results was judged at the 5\% level. The used test were Pearson coefficient to correlate between two normally distributed quantitative variables as well as Student t-test to compare between two studied

\section{Results}

Table (1) shows the distribution of students according to their sociodemographic data. Among all participants 79 (87.8\%) were female and 11(12.2\%) were male. Less than half of participants (43.3\%) were in the age group of 20-25 years followed by $28.9 \%$ in the age group over 25 years and 27.8 participants were of $18-20$ years. More than half of the students $(55.6 \%)$ were nursing and $44.4 \%$ of them were clinical laboratory specialty. Regarding level of education, nearly similar percent $(27.8 \%, 26.7 \%)$ of participants were level 8 and 6 respectively.

Table 1: Distribution of students according to their socio demographic data

\begin{tabular}{|c|c|c|}
\hline Socio-demographic data & No. & \% \\
\hline Age & & \\
\hline $18-20$ & 25 & 27.8 \\
$20-25$ & 39 & 43.3 \\
\hline Over 25 & 26 & 28.9 \\
\hline Sex Male & & \\
\hline Female & 11 & 12.2 \\
\hline Specialty & 79 & 87.8 \\
\hline Nursing & & \\
\hline Clinical laboratories Science & 40 & 55.6 \\
\hline Level of education & & 44.4 \\
\hline Level 5 & 20 & 22.2 \\
\hline Level 6 & 24 & 26.7 \\
\hline Level 7 & 21 & 23.3 \\
\hline Level 8 & 25 & 27.8 \\
\hline
\end{tabular}

Table (2) describes the students' knowledge, practice and attitudes regarding needle stick and sharp objects injuries infection prevention and control guidelines. In relation to knowledge, more 
than half $(54.4 \%)$ of the students have moderate knowledge regarding needle stick and sharp objects injuries. As for practice, $57.8 \%$ of the students had fair practice while $17.8 \%$ of them had good practice. In relation to attitude, more than two- thirds (76.7\%) of total students have positive attitude toward needle stick and sharp objects injuries infection prevention and control guidelines.

Table (2): Descriptive analysis of the student knowledge, practice and attitudes regarding needle stick and sharp objects injuries infection prevention and control guidelines $(n=90)$

\begin{tabular}{|l|c|c|}
\hline NSI \& infection control guidelines & No. & \% \\
\hline Knowledge & & \\
\hline Poor $(<50 \%)$ & 24 & 26.7 \\
\hline Fair $(50-<75 \%)$ & 49 & 54.4 \\
\hline Good $(\geq 75 \%)$ & 17 & 18.9 \\
\hline Total Score & \multicolumn{2}{|c|}{$10.56 \pm 2.92$} \\
\hline Percent Score & \multicolumn{2}{|c|}{$58.64 \pm 16.22$} \\
\hline Practice & \multicolumn{2}{|c|}{} \\
\hline Poor $(<50 \%)$ & 22 & 24.4 \\
\hline Fair $(50-<75 \%)$ & 52 & 57.8 \\
\hline Good $(\geq 75 \%)$ & 16 & 17.8 \\
\hline Total Score & \multicolumn{2}{|c|}{$3.38 \pm 1.13$} \\
\hline Percent Score & $26.30 \pm 18.79$ \\
\hline Attitude & 21 & 23.3 \\
\hline Negative $(<60 \%)$ & 69 & 76.7 \\
\hline Positive $(\geq 60 \%)$ & \multicolumn{2}{|c|}{$43.79 \pm 2.89$} \\
\hline Total Score & \multicolumn{2}{|c|}{$63.98 \pm 6.43$} \\
\hline Percent Score & \multicolumn{3}{|c|}{} \\
\hline
\end{tabular}

Table (3) shows the comparison between nursing and clinical laboratories science specialty according to students' total scores of knowledge, practice and attitude. Regarding knowledge, students in clinical laboratories specialty had higher mean scores (62.96 \pm 17.77) than those who were in nursing specialty (56.48 \pm 15.07$)$, However, the difference was not statistically significant $(\mathrm{p}=0.074)$. As for attitude, students in clinical laboratories and nursing specialty had nearly similar mean scores $(64.74 \pm 7.28,63.59 \pm$ 5.99) respectively, However, the difference was not statistically significant $(\mathrm{p}=0.428)$. In relation to practice, students in nursing specialty had higher mean scores $(59.44 \pm 21.34)$ than those who were in clinical laboratories specialty $(50.0 \pm 9.79)$, and the difference was statistically significant $(\mathrm{p}=0.005)$.

Table 3: Comparison between nursing and clinical laboratories science specialty according to students' total scores of knowledge, practice and attitude

\begin{tabular}{|l|c|c|c|c|}
\hline \multirow{3}{*}{ Scores } & \multicolumn{2}{|l|}{ Specialty } & \multirow{2}{*}{$\begin{array}{c}\text { Test } \\
\text { of sig. }\end{array}$} & p \\
\cline { 2 - 3 } & Nursing & $\begin{array}{l}\text { Clinical } \\
\text { laboratories } \\
\text { Science }\end{array}$ & & \\
\cline { 2 - 3 } Knowledge & $\mathbf{X} \pm$ SD & $\mathbf{X} \pm$ SD & & \\
Percent Score & 15.07 & $62.96 \pm$ & $\mathrm{t}=$ & 0.074 \\
\hline Practice & $59.44 \pm$ & $50.0 \pm$ & $\mathrm{t}=$ & $0.005^{*}$ \\
Percent Score & 21.34 & 9.79 & $2.876^{*}$ & \\
\hline Attitude & $63.59 \pm$ & $64.74 \pm$ & $\mathrm{t}=$ & 0.428 \\
Percent Score & 5.99 & 7.28 & 0.797 & \\
\hline
\end{tabular}

$t$ : Student t-test

*: Statistically significant at $p \leq 0.05$

Figure 1 shows the history NSIs among health care students. Approximately two-thirds (66.7\%) of the students had no history of exposure to NSIs, while $33.3 \%$ of them had no history.

\section{History of exposure to Needle Stick Injuries}

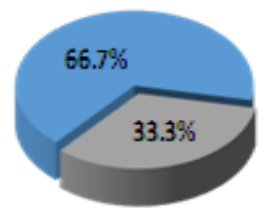

Figure 1: Distribution of history of NSIs among health care students

Figure (2) illustrates percentage of times of exposure to NSIs among health care students. Most of the students (42.2\%) reported that they exposed to NSIs once during their clinical training and only $4.4 \%$ had exposed five times or more to NSIs.

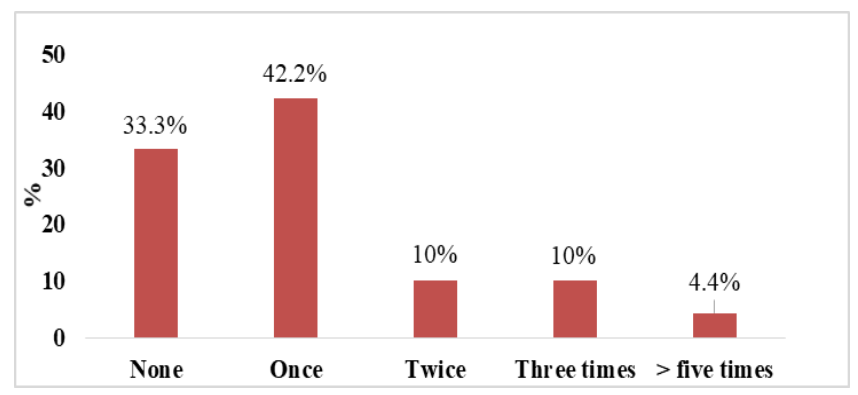

Figure (2): Percentage of number of exposure times to NSIs among health care students

Figure (3) shows the distribution of clinical procedures that cause NSIs among participants. Nearly similar percentage (40\%, 35.6\%) of the students stated that NSIs occurred during recapping of needle and blood sampling respectively.

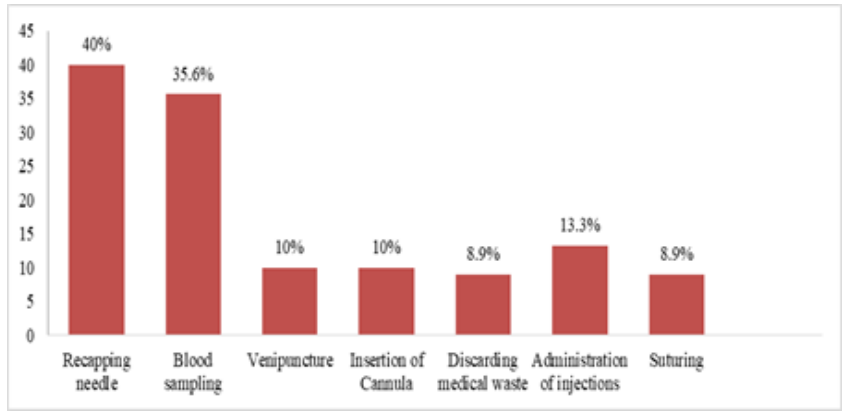

Figure (3): Distribution of clinical procedures that cause NSIs among health care students

Figure (4) reveals the availability of safety devices during clinical/laboratory. It was found that more than two-thirds $(71.1 \%$, $70 \%, 66.7)$ of students reported that safety syringe, blood collection needle and safety winged blood collection sets are available respectively.

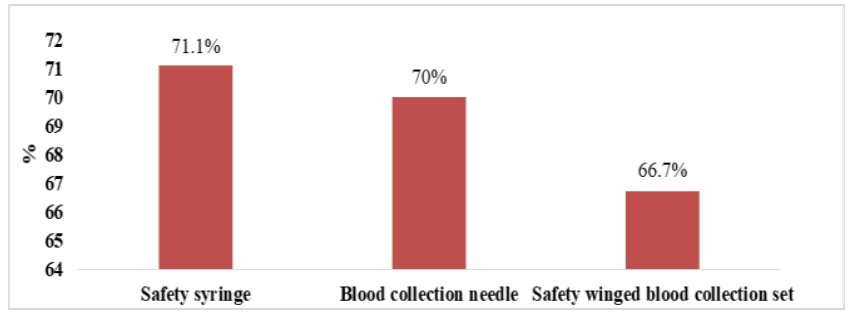

Figure (4): Distribution of the availability of safety devices during clinical/laboratory training 
Table (4) displays correlation between the students' knowledge, practice, and attitude scores, it was found that there is a significant correlation between student's knowledge and practice ( $\mathrm{r}=0.229$, $\mathrm{p}=0.030$ ) and the same was observed between practice and attitude $(\mathrm{r}=0.255, \mathrm{p}=0.015)$.

Table (4): Correlation between the students' knowledge, practice and attitude regarding NSIs $(n=90)$

\begin{tabular}{|l|c|c|}
\hline & $\mathrm{r}$ & $\mathrm{p}$ \\
\hline Knowledge vs. Practice & $0.229^{*}$ & $0.030^{*}$ \\
\hline Knowledge vs. Attitude & 0.037 & 0.732 \\
\hline Practice vs. Attitude & $0.255^{*}$ & $0.015^{*}$ \\
\hline
\end{tabular}

$r$ : Pearson coefficient

*: Statistically significant at $p \leq 0.05$

\section{Discussion}

The safe management and disposal of needles and other sharp objects are considered as an important part during clinical and practical training to protect health care students from the risk of blood borne pathogens. ${ }^{[22]}$ Thus, this study was conducted to see knowledge, incidence, practice and attitude of health care students towards needles and other sharp objects injuries.

In relation to knowledge, the overall knowledge regarding infection prevention and control guidelines to prevent needle stick and sharp objects injuries of the students in the current study was fair among about half of the students. This indicates the importance of the integration of infection control guidelines into the curriculum of nursing and paramedical students and the emphasis on its practice in the areas of clinical training. This study is in line with the results of Marjadi et. al. (2017) who found that respondents' NSI-related knowledge were generally moderate with a median score of 3 out of a maximum of 6 for knowledge. ${ }^{[23]}$ This consistency of findings despite the advancement in the infection control programs is alerting. Clinical instructors should increase students' training to assess clinical tasks and identify NSI risks that they will face. In addition, Lakshmi and Bhat (2015) found that students of paramedical course had adequate knowledge regarding NSIs. ${ }^{[21]}$ In contrast, the study conducted by Nawaeh et.al. (2019) reported that high incidence of NSIs among university nursing students due to deficiency of knowledge concerning needle stick. $^{[17]}$

Moreover, the current study revealed that nearly half of the students had knowledge about the universal precautions to prevent NSIs, but more than two third of them stated that single handed technique is used for recapping a needle. Also, most of the students didn't define the NSIs completely. This supported by the reports from the international guidelines that illustrated the safest method to dispose of a used needle is to put it in a sharps disposal container immediately to decrease the risk of NSIs. ${ }^{[2]}$ Thus, it is very essential to inform the students about all of these guidelines to avoid NSIs.

Only $46.7 \%$ of all students had good knowledge in relation to the diseases transmitted by NSIs. This study results is line with a study done by Marjadi et al (2017) who found that $10 \%$ of respondents had the knowledge that NSIs can cause HBV and $32.0 \%$ for HIV. ${ }^{[23]}$

Considering the incidence of NSIs, it was reported that two-thirds of the students experienced NSIs during their clinical training at least once. This can be explained that more than one-third of the students were in clinical laboratories sciences department who deals always with needles. Moreover $40 \%$ of those injured was during recapping needles. Also some of the students are Bridging students who completed a diploma degree in nursing and joined the college to earn a better degree, so they already working in some clinics and hospitals which mean more exposure to NSIs. According to the results of Rais et. al. (2013), it was discovered that $77 \%$ of HCWs experienced NSIs at least once (32\%). Furthermore, $66.6 \%$ of the medical students, $50 \%$ of nursing students and $40 \%$ of the paramedical students had experienced NSIs. ${ }^{[4]}$

In relation to the overall students' practice, it was found that about half of the students have moderate level of practice in relation to the use of infection prevention and control guidelines to prevent NSIs. Very good practice was noticed in the habit of the students in wearing gloves during minor procedures (100\%) and in the immediate disposal of the used needles into the sharp containers (90\%). Only $40 \%$ of them had reported the exposure of NSIs to their seniors and only $43.3 \%$ used the post exposure prophylaxis (PEP) after needle stick and sharp objects injuries. This is supported by the study of Singru and Banerjee (2008) who found that $50 \%$ of the affected participants informed the incidence of injury to concerned hospital authorities. ${ }^{[25]}$

The poor utilization of PEP indicated the poor awareness among the students of its importance and may be related to fear, sham or stigma of injury. This study results is in line with Vijay et. al. (2017) who found that about half of the HCWs have good practice in relation to NSIs and only about one-third of them reported their exposure to NSIs in their work. ${ }^{[24]}$ This emphasis that there are some areas in the infection control guidelines that needs extra efforts and more stress during clinical training, especially regarding recapping of needles, PEP and the importance of reporting and the reporting mechanism in order to protect themselves from NSIs.

In consideration to the attitude, about two-thirds of the students had positive attitudes toward needle stick and sharp objects injuries infection prevention and control guidelines, where almost all of them had agreed that every student is susceptible to NSIs, training programs can reduce the prevalence of NSIs, the safe handling of needles can reduce the risk of injury and the importance of HBV vaccine to all students. This can be explained by that the students had acquired all the data needed to shape their attitudes in their undergraduate studies. This is in line with what was discovered by Nawafle et. al. (2017) who had found that most of the students had positive attitudes towards NSIs. ${ }^{[9]}$

\section{Conclusion}

It was concluded that students in this study have fair knowledge and practice as well as the majority of them had positive attitudes regarding needle stick and sharp objects injuries infection prevention and control guidelines. Providing health education and training programs to the health care students about sharps injuries have a great effect on decreasing the incidence.

Thus, it is recommended that regular education sessions for all nursing and paramedical students about the updated guidelines related to handling and disposal of sharps. Furthermore, special concerns should be given to the role of PEP, the recapping of needles and the importance and mechanism of reporting sharps injuries. In addition, health care students should undergo compulsory immunization program prior to their enrolment. A 
standing order procedure (SOP) should be formulated regarding sharps injuries in all educational and health institutions. It should also outline precautions to be taken when dealing with blood and body fluids.

\section{References}

[1] Center, I., Estimated number of US occupational percutaneous injuries and mucocutaneous exposures to blood or at-risk biological substances. IHCWSC at university of Virginia, 1999.

[2] Moazeni-Bistgani, M., S. Shahrjerdi, and N. Khosravi, Evaluation of Preventive Interventions in Reporting Needle Stick Injuries among Health Care Workers. International Journal of Hospital Research, 2014. 3(1): p. 31-36.

[3] Singh, B., B. Paudel, and S. Kc, Knowledge and practice of health care workers regarding needle stick injuries in a tertiary care center of Nepal. Kathmandu University Medical Journal, 2015. 13(3): p. 230-233.

[4] Rais, N. and H.M. Jamil, Prevalence of needle stick injuries among health care providers. Int $\mathrm{J}$ Endorsing Health Sci Res, 2013. 1(2): p. 73-79.

[5] Prasuna, J., et al., Occurrence and knowledge about needle stick injury in nursing students. Journal of Ayub Medical College Abbottabad, 2015. 27(2): p. 430-433.

[6] El Tawil, F., Knowledge and prevalence of needle stick injuries among nurses working in hemodialysis units in Al Jouf region, Saudi Arabia. IOSR J Nurs Health Sci, 2016. 5: p. 13-19.

[7] Abozead, S.E.-S., et al., Knowledge and practices of Jordanian nurses on needlestick injuries: An evaluative study. Infectious Diseases in Clinical Practice, 2015. 23(1): p. 21-25.

[8] Hashmi, A., S. Al Reesh, and L. Indah, Prevalence of needle-stick and sharps injuries among healthcare workers, Najran, Saudi Arabia. Epidemiology, 2012. 2(2): p. 117.

[9] Nawafleh, H.A., et al., Investigating needle stick injuries: Incidence, knowledge and perception among South Jordanian nursing students. Journal of Nursing Education and Practice, 2017. 8(4): p. 59-69.

[10] Hasak, J.M., et al., Prevalence of needlestick injuries, attitude changes, and prevention practices over 12 years in an urban academic hospital surgery department. Annals of surgery, 2018. 267(2): p. 291-296.

[11] Weiss, E.S., et al., Human immunodeficiency virus and hepatitis testing and prevalence among surgical patients in an urban university hospital. The American journal of surgery, 2007. 193(1): p. 55-60.
[12] Council Directive, E., Implementing the framework agreement on prevention from sharps injuries in the hospital and health care sector. 2010.

[13] Dulon, M., et al., Causes of needlestick injuries in three healthcare settings: analysis of accident notifications registered six months after the implementation of $\mathrm{EU}$ Directive 2010/32/EU in Germany. Journal of Hospital Infection, 2017. 95(3): p. 306-311.

[14] Sohn, J.-W., et al., Mental health of healthcare workers who experience needlestick and sharps injuries. Journal of occupational health, 2006. 48(6): p. 474-479.

[15] Alert, N., Preventing needlestick injuries in health care settings. DHHS (NIOSH) Publication, 1999. 1999: p. 2000-108.

[16] Verbeek, J., et al., Building an evidence base for occupational health interventions. Scandinavian journal of work, environment \& health, 2004. 30(2): p. 164-170.

[17] Nawafleh, H.A., et al., The Incidence and Circumstances of Needle Sticks Injury (NSI) Among Arab Nurses Students: Comparative Study. Health Science Journal, 2019. 13(2): p. 1-6.

[18] Adams, D., Needlestick and sharps injuries: practice update. Nursing Standard, 2012. 26(37).

[19] Batool, A., et al., Knowledge, attitude and practices of dentists about Hepatitis B and C infection in Lahore. Pakistan Journal of Medical Research, 2012. 51(3): p. 93.

[20] Singh, G., et al., Assessment of knowledge, attitude and practice towards post exposure prophylaxis for HIV among health care professionals in Lahore. Occup. Med. Health Aff, 2015. 3: p. 208-18.

[21] Sangeetha Lakshmi, G. and R. Bhat, A study on awareness of needle sticks injury in students undergoing paramedical course. IOSR-JDMS, 2015. 14(11): p. 34-8.

[22] Health, N.I.f. and C. Excellence, Infection: prevention and control of healthcare-associated infections in primary and community care. 2012, NICE London.

[23] Marjadi, B., et al., Needlestick injury among medical students in an Australian university. Journal of Infectious Diseases and Epidemiology, 2017. 3(2).

[24] Vijay, C., A. Joe, and N. Ramesh, Knowledge of needle sticks injuries and its prevention among interns and post graduate students working at a tertiary health care centre, Bangalore. International Journal of Community Medicine and Public Health, 2017. 4(7): p. 2443-2448.

[25] Singru, S.A. and A. Banerjee, Occupational exposure to blood and body fluids among health care workers in a teaching hospital in Mumbai, India. Indian journal of community medicine: official publication of Indian Association of Preventive \& Social Medicine, 2008. 33(1): p. 26. 